UDC 004.021:530.182.1

DOI: $10.22363 / 2312-9735-2018-26-3-244-251$

\title{
Simple Model of Nonlinear Spin Waves in Graphene Structures
}

\author{
D. S. Kulyabov*†, K. P. Lovetskiy*, Le Anh Nhat* \\ * Department of Applied Probability and Informatics \\ Peoples' Friendship University of Russia (RUDN University) \\ 6 Miklukho-Maklaya str., Moscow, 117198, Russian Federation \\ ${ }^{\dagger}$ Laboratory of Information Technologies \\ Joint Institute for Nuclear Research \\ 6 Joliot-Curie, Dubna, Moscow region, 141980, Russian Federation
}

A series of theoretical and experimental works is known which investigated the magnetic properties of graphene structures. This is due, among other things, to the prospects of using graphene as a material for the needs of the future nanoelectronics and spintronics. In particular, it is known about the presence of ferromagnetic properties at temperatures up to $200 \mathrm{C}$ and above in a single-layer graphene films that are free from impurities. Previously there was proposed a quantum field theoretical model describing the possible mechanism of ferromagnetism in graphene as a result of spontaneous breaking of spin symmetry of the surface density of valence electrons. The possible spatial configurations of the localized spin density were described.

In this paper we investigate such spatially localized nonlinear spin configurations of the valence electron density on the graphene surface such as kinks, and their interactions, as well as quasibound metastable states of the interacting kinks and antikinks, that are breathers. The spectrum of such breathers is investigated. It is shown that under certain conditions, this spectrum has a discrete sector, which, in turn, allows us to speak about the possibility of coherent quantum generation of spin waves in graphene structures, which is important in terms of practical applications in nanoelectronics and spintronics.

Key words and phrases: graphene, solitons, kinks, breathers, nonlinear models

\section{Prerequisites of Building a Model of the Graphene Ferromagnetizm}

Today the standard theoretical model of electronic structure of single-layer graphene film, which had been proposed in [1] and was investigated in a number of works [2-4] is well known. Within this model, not all experimentally observed properties of graphene can be satisfactorily explained. In several works (for example, see [5]) a high-temperature ferromagnetizm not caused by any of three possible reasons: impurities, defects, borders, was described, and in [6] processes of spin-polarized current pulses in the graphene film were experimentally observed. We offer and investigate the theoretical model describing collective spin- electronic properties of the single-layered graphene structures forming two-dimensional surfaces, connected with existence on these surfaces of nonzero function of distribution of the spin density formed as a result of spontaneous violation of spin symmetry of valency electrons of atoms of carbon on specified surfaces. As the spin density is proportional to magnetization density, this model allows describing ferromagnetic properties of the graphene structures.

Within the limits of offered model transition from consideration of the discrete twodimensional carbon lattice forming graphene film, to the continuous two-dimensional surface tensed on this lattice is carried out. The specified two-dimensional surface is configuration space of the model. Thus, we carry out transition to the continual field model. Such approach seems to be natural as it is known that, in particular, in graphene structures the fourth valence sp-electron of carbon is collective, and its wave function isn't localized on a lattice knot. Thus spin states of the wave function of valence electrons

Received $29^{\text {th }}$ June, 2018.

The publication has been prepared with the support of the "RUDN University Program 5-100" and funded by Russian Foundation for Basic Research (RFBR) according to the research project No 16-07-00556. 
system of a graphene layer define some function of spin density on two-dimensional configuration space of the model. We will consider this function, as some (classical) nonlinear function of a field on a two-dimensional surface. In considered model function of spin density is admissible trivial, identically equal to zero. Being based on the above-stated experimental data, suppose, that this symmetric field configuration can spontaneously be broken to some physically observed

As we noted earlier [7,8] and as recently it was confirmed in works [9,10], within classical nonrelativistic field model the analog of the well-known Goldstone theorem, according to which each broken generator of initial symmetry of a field system corresponds to the massless scalar not charged boson (which in our case may be called spinon) takes place.

In this case spontaneous violation of spin symmetry within the offered model should lead to existence on graphene surfaces of quasi-particles - spinons (magnons) being vector bosons in the 3rd dimensional physical space and scalar bosons in two-dimensional configuration space of model as a projection the quasi-particle spin on configuration space of the model is always equal to zero.

From the physical point of view essentially that existence of collective effects in spinon system, caused by influence of the total magnetic field created by all spinons on each spinon and spontaneous violation of spin symmetry in such system means nonlinearity of the corresponding field equations and, as a result, existence of the possibility on graphene surfaces of the soliton configurations depending on a form and topology of a surface.

Besides, existence of the collective nonlinear interactions in spinon ensemble should lead to emergence of effective spinon mass by Higgs's mechanism that also should affect observable physical consequences though owing to a small value of such interactions it is hardly possible to expect great values of this mass.

So, it is visible that the equations for the required scalar field which has been set on some two-dimensional surface, should be nonlinear and certain on this surface any, generally speaking, forms and topology. The form and topology in this case define boundary conditions for the field function. The specified function defines conditions of existence, a configuration and dynamics of quasi-particles of this field on the set two-dimensional surface.

In particular, field equations, describing massless nonlinear scalar quasi-particles, known in the quantum theory, possess above specified properties.

Thus, for the description of spinon excitations on graphene surfaces we use one of options of nonlinear field model that allows calculating eigen solutions, effective masses, topological invariants, energy spectra, dynamics of various nonlinear spinon configurations, and other characteristics of the spinon statistical ensemble.

Let's make transition from a discrete set of knots of a 2D hexagonal lattice in which not coupled electrons can be localized, both the corresponding electronic and spin density, to the continual representation of the corresponding configuration space.

The classical field model describing spontaneously broken symmetry is nonlinear. Among nonlinear models the elementary and the known $\lambda \varphi^{4}$ model is rather well studied. We believe $[7,8]$ that as a first approximation we can describe with its help characteristics of spin waves of interest to us, their spectra in graphene, ferromagnetic domain structure and other characteristics important for the practical applications.

The model has kink and antikink exact solutions and their quasibounded states (breathers), which we will obtain numerically. We will use the energy of the kinkantikink interaction $[7,8]$ for the numerical solution of the Schrödinger equation for modeling quantum dynamics of breathers, underlying the description of spin waves. In model there are quasibounded kink-antikink states, having a discrete spectrum. It allows to put, in particular, a problem of creation of inverse density of population and implementation of quantum generation of spin waves.

Further we will discuss the obtained results and their consequences. 


\section{Nonlinear Model}

Let's consider as an example the nonlinear model $\lambda \varphi^{4}$ in order to show results of qualitative and numerical research of spin waves in a single-layered graphene film. Let's consider nonlinear model of a scalar field on a two-dimensional surface with the Lagrangian:

$$
L\{\varphi\}=\frac{1}{2}\left(\partial_{\nu} \varphi \partial^{\nu} \varphi\right)-\frac{\lambda}{4}\left(\varphi^{2}-\varphi_{0}^{2}\right)^{2}, \quad \nu=0,1,2 ; \varphi=\varphi(x, y, t) ; \varphi_{0}>0 ; \lambda>0 .
$$

Field function here is proportional to two-dimensional spin density.

The equations of a field and boundary conditions look like

$$
\left[\partial_{\nu} \partial^{\nu}-\lambda \varphi_{0}^{2}\right] \varphi-\lambda \varphi^{3}=0 ; \quad|\varphi(x, y, t)|<\varphi_{0}, \quad \forall x, y, t .
$$

It is known that this nonlinear equation has a set of static vacuum solutions

$$
\varphi_{\mathrm{vac} \pm}= \pm \varphi_{0}
$$

And also kink-antikink solutions

$$
\varphi_{ \pm}(x)= \pm \varphi_{0} \tanh \left(\sqrt{\frac{\lambda \varphi_{0}^{2}}{2}} x\right)
$$

In the field of zero kink and antikink have the domain wall dividing areas with opposite signs of magnetization. The elementary magnetic moment in our model is the full magnetic moment of an elementary cell.

We investigate system of interacting kink and antikink, located at a distance $a(t)$ one from another. Let's choose field function in a way

$$
\varphi(x, a)=\left[\varphi_{+}(x+a)+\varphi_{-}(x-a)-\varphi_{0}\right] ; \quad a>0 .
$$

We see that field function (5) at small values of $a$ spatially is localized near $x=0$ and has the following asymptotics:

$$
\begin{gathered}
\varphi(x,+\infty)=-\varphi_{0} \\
\varphi(+\infty, a)=-\varphi_{0} ; \quad \varphi(-\infty, a)=-\varphi_{0} \\
\varphi_{x}^{\prime}(+\infty, a)=0 ; \quad \varphi_{x}^{\prime}(-\infty, a)=0
\end{gathered}
$$

We also see that kink and antikink, divided on rather big (in comparison with "thickness" of a kink) distance, nevertheless, keep the form.

Let's consider the Hamilton function of the system:

$$
H\{\varphi, a\}=\int_{-\infty}^{+\infty} \mathrm{d} x\left\{\left[\partial_{\nu} \varphi(x, a) \partial^{\nu} \varphi(x, a)\right]+\frac{\lambda}{2}\left[\varphi(x, a)^{2}-\varphi_{0}^{2}\right]^{2}\right\} .
$$

This function can be considered as a function of total energy of the kink-antikink system, and we can formally investigate its dependence on $a$. Dependence of a Hamiltonian on $a$ corresponds to dependence of potential energy of the kink-antikink interaction on a distance between them. If there are minima of this function, it is natural to expect existence of discrete spectra of the bound states in the kink-antikink system near these minima. It will be required breathers. 
For quantum mechanical stationary wave function of a breather it is possible to write down the Schrödinger equation:

$$
\left[-\frac{\hbar^{2}}{2 m_{b}} \frac{\mathrm{d}^{2}}{\mathrm{~d} a^{2}}+U\{\varphi, a\}\right] \Psi_{b}(a)=E \Psi_{b}(a) .
$$

Here $m_{b}$ is an effective mass of a breather which is equal to the sum of masses of kink and antikink, $U\{\varphi, a\}$ is a potential part of a total energy of the breather, depending from $a, E$ is an energy of a state. Movement of a breather on the generalized coordinate $a$ physically corresponds to a distance change between kink and antikink.

Let's find the bound states of the kink-antikink system near a minimum of the potential of interaction. This problem can be solved numerically.

\section{Numerical Calculations for the Model of Nonlinear Spin Waves in Graphene}

Numerical modeling studies start with the approximate solution (5) of (2). To begin with we calculate the dependence $V(a)=H\{\varphi, a\}$ of (6). Calculations were performed using an adaptive procedure, the integration of functions, based on the method of NewtonCotes with different numerical values of the parameters $\lambda$ and $\varphi_{0}$. As an illustration we plot the graph of the function $V_{\lambda, \varphi_{0}}(a)$ at $\lambda=0.2$ and $\varphi_{0}=4.0$ (see Fig. 1).

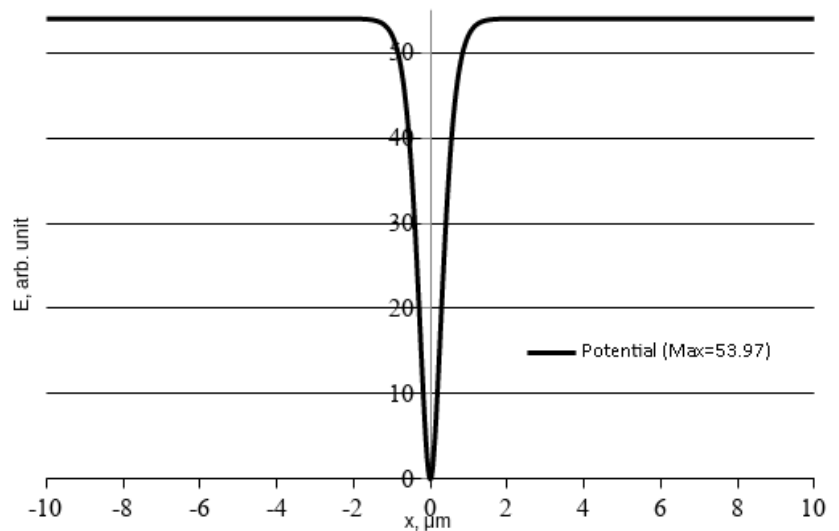

Figure 1. The graph of potential energy breather

As can be seen from the graph, the discrete spectrum of (7) is located in the interval $[0.0 ; 53.96954]$. With the numerically solved (grid) function $V_{\lambda, \varphi_{0}}(a)$ we solve the Schrödinger equation (7) by the Ritz method using Hermite functions as coordinate functions. The Ritz method reduces the problem on the axis of the differential equation (7) into eigenvalue and eigenvectors problem for the Ritz matrix, as calculated by the formulas:

$$
M_{i j}\left\{\lambda, \varphi_{0}\right\}=\left\langle\psi_{i}\left|\left(-\frac{\hbar^{2}}{2 m\left\{\lambda, \varphi_{0}\right\}} \frac{\mathrm{d}^{2}}{\mathrm{~d} a^{2}}+V_{\lambda, \varphi_{0}}(a)\right)\right| \psi_{j}\right\rangle
$$

where $\psi_{i}$ are Hermite functions.

The eigenvectors are sought in the form

$$
\varphi_{j}\left(\lambda, \varphi_{0} ; a\right)=\sum_{i} C_{j}^{i}\left\{\lambda, \varphi_{0}\right\} \psi_{i}
$$


so that the problem on the eigenvalues and eigenvectors is formulated as

$$
\hat{M}\left\{\lambda, \varphi_{0}\right\} \vec{C}_{j}\left\{\lambda, \varphi_{0}\right\}=E_{j}\left\{\lambda, \varphi_{0}\right\} \vec{C}_{j}\left\{\lambda, \varphi_{0}\right\}
$$

Calculating matrix elements (8) and a solution of (10) were performed in a program. As an illustration we give the five lowest calculated eigenvalues belonging to the discrete spectrum of the operator (7), and the corresponding eigenvectors (grid function) given by (9) for the numerical values of the parameters $\lambda=0.2$ and $\varphi_{0}=4.0$ (see Fig. 2).
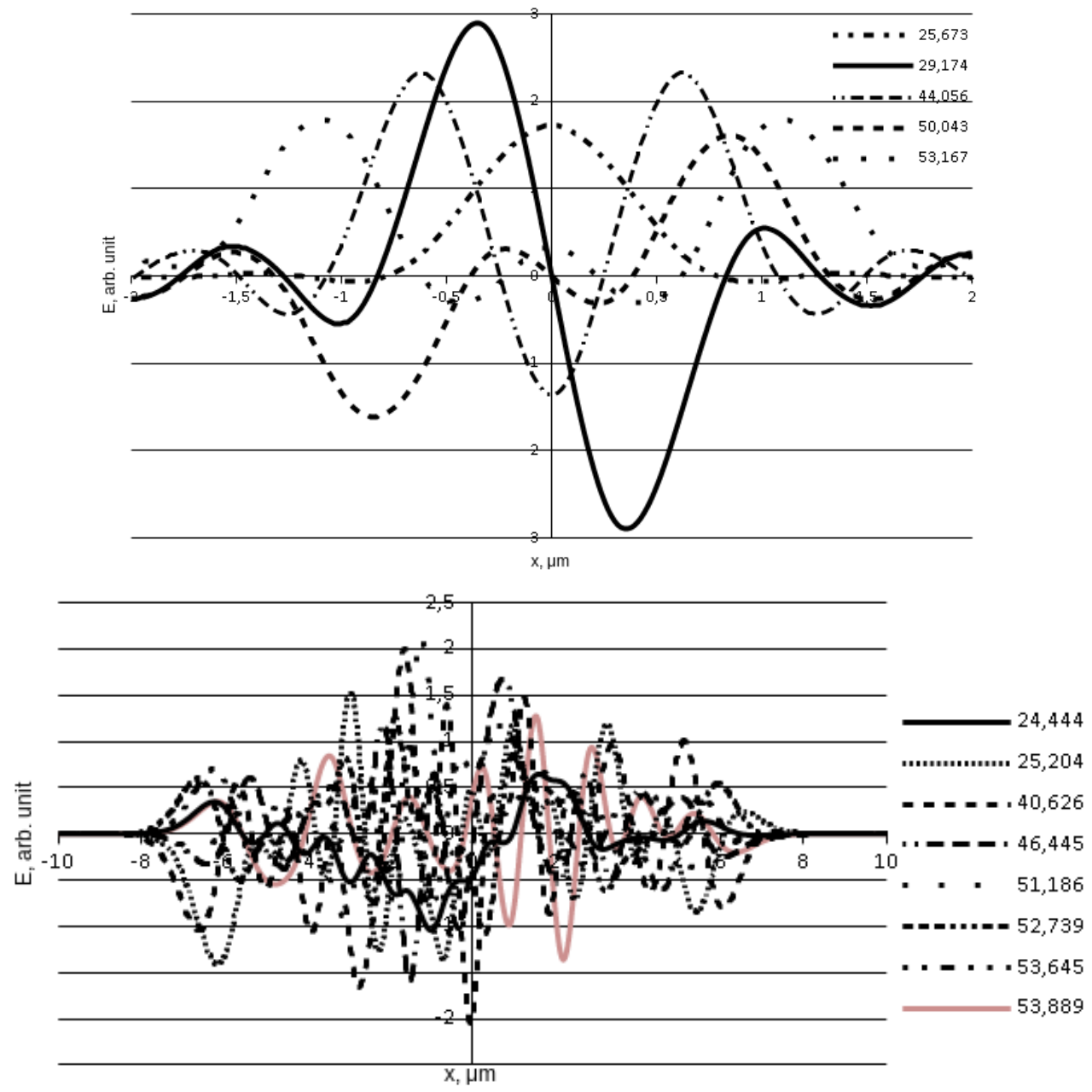

Figure 2. The eigenvalues and eigenfunctions of the original problem

Even these examples indicate a non-trivial structure of the spectrum of eigenvalues of the operator (7). Namely, the structure of the spectrum in Fig. 3. shows the fundamental possibility of population inversion.

This, in turn, confirms our thesis (see $[7,8]$ ) about the possibility of generation of spin waves. 

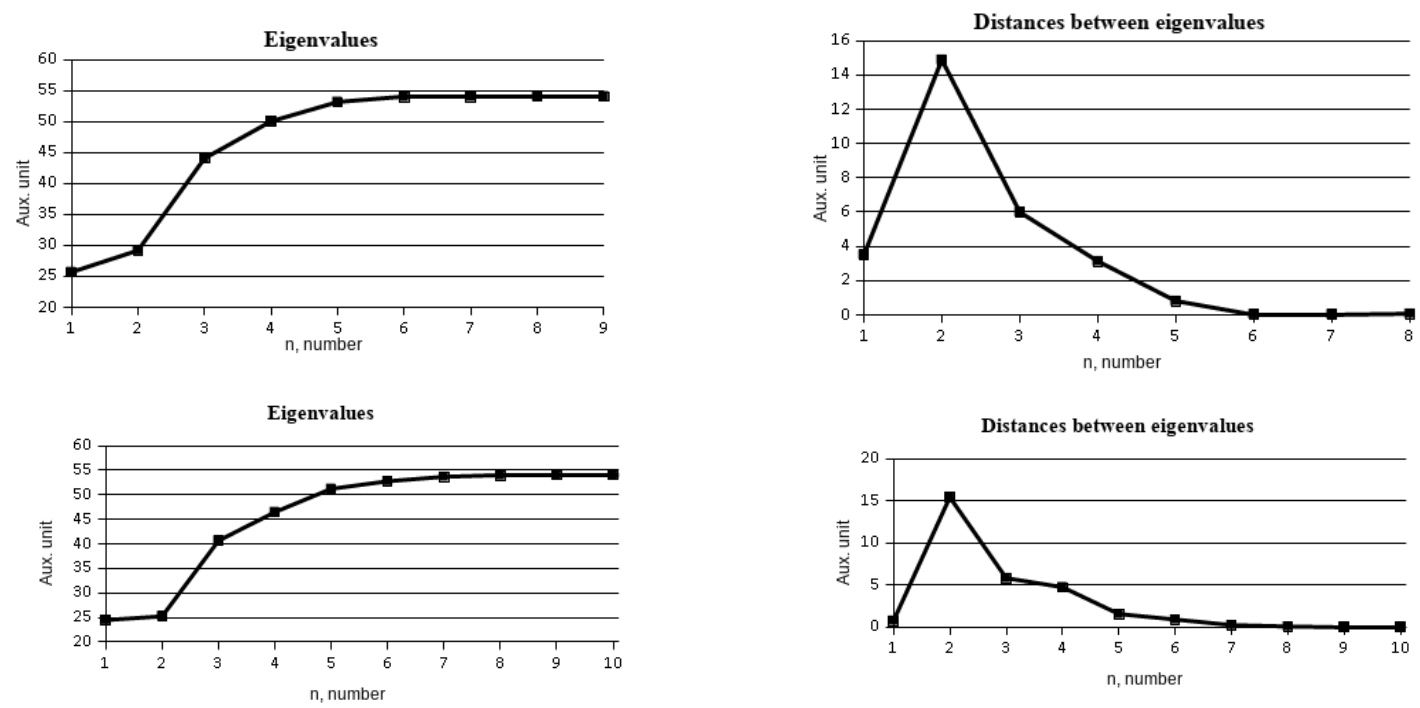

Figure 3. The relative position of the spectral values of the breather

\section{Discussions and conclusions}

Results of numerical calculations allow to make a number of practically important conclusions. First of all, we see that within the offered nonlinear model existence of metastable kink-antikink bound states for the function of spin density on a two-dimensional graphene surface is possible. These states may form a discrete spectrum. Thus numerical calculations show that interval change between the next levels generally decreases with the energy growth, and since some value of energy the spectrum becomes continuous. At the same time we see that the interval between the next levels, in some local cases, isn't monotonous function, and has local extrema. Existence of such extrema allows to argue that it is possible to expect existence in a energy spectrum of spin-breathers in graphene film of metastable states, which lifetime is more than lifetime of the states being below on energy. In this case we can speak about possibility of creation of inverse density of population in spectra of breathers, and, respectively, about quantum coherent generation of spin waves.

\section{References}

1. P. R. Wallace, The Band Theory of Graphite, Physical Review 71 (1947) 622-634.

2. D. V. Kolesnikov, V. A. Osipov, The Continuum Gauge Field-Theory Model for Low-Energy Electronic States of Icosahedral Fullerenes, European Physical Journal B 49 (2006) 465. arXiv:cond-mat/0510636.

3. K. S. Novoselov, A. K. Geim, S. V. Morozov, D. Jiang, M. I. Katsnelson, I. V. Grigorieva, S. V. Dubonos, A. A. Firsov, Two-Dimensional Gas of Massless Dirac Fermions in Graphene, Nature 438 (2005) 197-200. doi:10.1038/nature04233.

4. N. M. R. Peres, Electronic Properties of Disordered Two-Dimensional Carbon, Physical Review B 73 (2006) 12541. doi:10.1103/PhysRevB.73.125411.

5. Y. Wang, Y. Huang, Y. Song, Z. X., Y. Ma, J. Liang, Y. Chen, Room-Temperature Ferromagnetism of Graphene, Nano Lett. 9 (2009) 220-224.

6. N. Tombros, C. Jozsa, M. Popinciuc, H. T. Jonkman, B. J. van Wees, Electronic Spin Transport and Spin Precession in Single Graphene Layers at Room Temperature, Nature 448 (2007) 571-574. 
7. D. D. Grachev, Y. P. Rybakov, L. A. Sevastyanov, E. F. Sheka, Ferromagnetism in graphene and fullerene structures. theory, modelling, experiment, Bulletin of Peoples' Friendship University of Russia. Series Mathematics, Information Sciences, Physics (1) (2010) 22-27.

8. D. D. Grachev, L. A. Sevastyanov, The Quantum Field Model of the Ferromagnetism in Graphene Films, Nanostructures, Mathematical Physics and Modelling 4 (2011) $5-15$.

9. T. Brauner, Spontaneous Symmetry Breaking and Nambu-Goldstone Bosons in Quantum Many-Body Systems, Symmetry 2 (2010) 609-657. doi:10.3390/sym2020609.

10. H. Watanabe, H. Murayama, Unified Description of Non-Relativistic NambuGoldstone Bosons, Physical Review Letters 108 (2012) 25160.

УДК 004.021:530.182.1

DOI: $10.22363 / 2312-9735-2018-26-3-244-251$

\title{
Простейшая модель нелинейных спиновых волн в графеновых структурах
}

\author{
Д. С. Кулябов*†, К. П. Ловецкий*, Ле Ань Ньат* \\ ${ }^{*}$ Кафедра прикладной информатики и теории вероятностей \\ Российский университет дружбъ народов \\ ул. Миклухо-Маклал, д. 6, Москва, Россия, 117198 \\ † Лаборатория информационных технологий \\ Обгединённый институт ядерных исследований \\ ул. Жолио-Кюри, д. 6, г. Дубна, Московская область, Россия, 141980
}

Известен ряд экспериментальных и теоретических работ, в которых исследовались магнитные свойства графеновых структур. Это вызвано перспективами использования графена в качестве материала для нужд будущей наноэлектроники и спинтроники. В частности, известно о наличии ферромагнитных свойств при температурах до $200^{\circ} \mathrm{C}$ и выше в однослойных плёнках графена, свободных от примесей. Ранее была предложена модель квантового поля, описывающая возможный механизм ферромагнетизма в графене в результате спонтанного нарушения спиновой симметрии поверхностной плотности валентных электронов. Описаны возможные пространственные конфигурации локализованной спиновой плотности.

В этой работе исследуются пространственно локализованные нелинейные спиновые конфигурации плотности валентных электронов на поверхности графена, такие как кинки, их взаимодействие, а также метастабильные состояния взаимодействующих кинков и антикинков, являющихся бризерами. Исследован спектр бризеров. Показано, что при определённых условиях этот спектр имеет дискретный сектор, что, в свою очередь, позволяет говорить о возможности когерентной квантовой генерации спиновых волн в графеновых структурах, что важно с точки зрения практического применения в наноэлектронике и спинтронике.

Ключевые слова: графен, солитоны, кинки, бризеры, нелинейные модели

\section{Литература}

1. Wallace P. R. The Band Theory of Graphite // Physical Review. — 1947. — Vol. 71. Pp. 622-634.

2. Kolesnikov D. V., Osipov V. A. The Continuum Gauge Field-Theory Model for Low-Energy Electronic States of Icosahedral Fullerenes // European Physical Journal B. - 2006. - Vol. 49. - P. 465.

3. Two-Dimensional Gas of Massless Dirac Fermions in Graphene / K. S. Novoselov, A. K. Geim, S. V. Morozov et al. // Nature. — 2005. - Vol. 438. - Pp. 197-200. DOI: $10.1038 /$ nature04233.

4. Peres N. M. R. Electronic Properties of Disordered Two-Dimensional Carbon // Physical Review B. — 2006. - Vol. 73. — P. 12541. — DOI: 10.1103/PhysRevB.73.125411. 
5. Room-Temperature Ferromagnetism of Graphene / Y. Wang, Y. Huang, Y. Song et al. // Nano Lett. — 2009. - Vol. 9. — Pp. 220-224.

6. Electronic Spin Transport and Spin Precession in Single Graphene Layers at Room Temperature / N. Tombros, C. Jozsa, M. Popinciuc et al. // Nature. - 2007. Vol. 448. - Pp. 571-574.

7. Ферромагнетизм в графеновых и фуллереновых наноструктурах. Теория, моделирование, эксперимент / Д. Д. Грачёв, Ю. П. Рыбаков, С. Л. А., Ш. Е. Ф. // Вестник Российского университета дружбы народов. Серия: Математика. Информатика. Физика. - 2010. - № 1. - С. 22-27.

8. Grachev D. D., Sevastyanov L. A. The Quantum Field Model of the Ferromagnetism in Graphene Films // Nanostructures, Mathematical Physics and Modelling. - 2011. Vol. 4. - Pp. 5-15.

9. Brauner T. Spontaneous Symmetry Breaking and Nambu-Goldstone Bosons in Quantum Many-Body Systems // Symmetry. - 2010. — Vol. 2. — Pp. 609-657. DOI: $10.3390 /$ sym2020609.

10. Watanabe H., Murayama H. Unified Description of Non-Relativistic Nambu-Goldstone Bosons // Physical Review Letters. - 2012. — Vol. 108. — P. 25160.

(C) Kulyabov D. S., Lovetskiy K.P., Le Anh Nhat, 2018

Для цитирования:

Kulyabov D.S., Lovetskiy K. P., Le Anh Nhat Simple Model of Nonlinear Spin Waves in Graphene Structures // RUDN Journal of Mathematics, Information Sciences and Physics. — 2018. - Vol. 26, No 3. - Pp. 244-251. — DOI: 10.22363/2312-9735-201826-3-244-251.

\section{For citation:}

Kulyabov D. S., Lovetskiy K. P., Le Anh Nhat Simple Model of Nonlinear Spin Waves in Graphene Structures, RUDN Journal of Mathematics, Information Sciences and Physics 26 (3) (2018) 244-251. DOI: 10.22363/2312-9735-2018-26-3-244-251.

\section{Сведения об авторах:}

Кулябов Дмитрий Сергеевич - доцент, доктор физико-математических наук, доцент кафедры прикладной информатики и теории вероятностей РУДН (e-mail: kulyabov_ds@rudn.university, тел.: +7(495)9520250)

Ловецкий Константин Петрович - доцент, кандидат физико-математических наук, доцент кафедры прикладной информатики и теории вероятностей РУДН (e-mail: lovetskiy_kp@rudn.university, тел.: +7(495)9522572)

Ле Ань Ньат (Социалистическая Республика Вьетнам) - аспирант кафедры прикладной информатики и теории вероятностей РУДН (e-mail: leanhnhat@tuyenquang . edu.vn, тел.: +7(495)9522572)

\section{Information about the authors:}

Kulyabov D.S. - Associate Professor, Doctor of Sciences in Physics and Mathematics, Associate Professor of Department of Applied Probability and Informatics of Peoples' Friendship University of Russia (RUDN University) (e-mail: kulyabov_ds@rudn.university, phone: +7(495)9520250)

Lovetskiy K.P. - Associate Professor, Candidate of Sciences in Physics and Mathematics, Associate Professor of Department of Applied Probability and Informatics of Peoples' Friendship University of Russia (RUDN University) (e-mail: lovetskiy_kp@rudn.university, phone: +7(495)9522572)

Le Anh Nhat (Socialist Republic of Vietnam) - PhD student of Department of Applied Probability and Informatics of Peoples' Friendship University of Russia (RUDN University) (e-mail: leanhnhat@tuyenquang.edu.vn, phone: +7(495)9522572) 